\title{
REFORMA AGRÁRIA E ASSENTAMENTOS RURAIS EM MATO GROSSO DO SUL
}

\author{
AGRARIAN REFORM AND RURAL SETTLEMENTS IN MATO \\ GROSSO DO SUL
}

\author{
Fabiano Coelho ${ }^{1}$ \\ André Alexandre Ricco de Freitas ${ }^{2}$
}

\begin{abstract}
RESUMO: Na história do Brasil, um país que se constituiu emaranhado ao latifúndio, terra é sinônimo de poder. A luta pela terra no tempo presente carrega tensões e marcas de uma história inacabada, em que presente/passado e passado/presente se misturam e se ressignificam, todavia, a histórica concentração de terras permanece. A reforma agrária no estado de Mato Grosso do Sul (MS) e no Brasil se processa, em especial, a partir das lutas empreendidas pelos movimentos sociais rurais e das contradições da política agrícola nacional. A criação de assentamento rurais constitui o principal instrumento da política de reforma agrária. Nesse sentido, o artigo reflete sobre a criação de assentamentos rurais no estado de MS, entre os anos de 1984 e 2013. Além das bibliografias sobre o tema, utilizou-se dados do Instituto de Colonização e Reforma Agrária (INCRA), por meio do Sistema de Informações de Projetos de Reforma Agrária (SIPRA). A pesquisa soma-se a outros investimentos em compreender a complexidade dos caminhos e descaminhos da luta pela terra e na criação de assentamentos rurais no Brasil, a partir do estado de MS.
\end{abstract}

PALAVRAS-CHAVE: Mato Grosso do Sul; Reforma Agrária; Assentamentos Rurais.

\footnotetext{
1 Pós-Doutorando em História Social pelo Programa de Pós-Graduação em História da Universidade Federal Fluminense (PPGH/UFF). Doutor em História pelo Programa de PósGraduação em História da Universidade Federal da Grande Dourados (PPGH/UFGD). Docente dos Cursos de Graduação e Pós-Graduação (Mestrado e Doutorado) em História da UFGD. Integra, na qualidade de pesquisador associado, o Instituto Nacional de Ciência e Tecnologia Proprietas: História Social das Propriedades e Direitos de Acesso. Bolsista CAPES/Brasil. Email: fabianocoelho@ufgd.edu.br. Orcid: 0000-0003-0294-5174.

${ }_{2}$ Mestre em Sociologia pelo Programa de Pós-Graduação em Sociologia da Universidade Federal da Grande Dourados (PPGS/UFGD). Analista em Reforma e Desenvolvimento Agrário na Superintendência Regional do Instituto Nacional de Colonização e Reforma Agrária (INCRA) no estado da Paraíba (SR/18/PB). E-mail: advandrericco@ hotmail.com . Orcid: 00000002-8175-8256.
} 
ABSTRACT: In the history of Brazil, a country that became entangled with the latifundium, land is synonymous with power. The struggle for land in the present time carries tensions and marks of na unfinished history, in which present/past and past/present are mixed and re-signified, however, the historical concentration of lands remains. Agrarian reform in the state Mato Grosso do Sul (MS) and in Brazil takes place, in particular, based on the struggles undertaken by rural social movements and the contradictions of the national agricultural policy. The creation of rural settlements is the main instrument of the agrarian reform policy. In this sense, the article reflects on the creation of rural settlements in the state of MS, between the years 1984 and 2013. In addition to the bibliographies on the topic, data from the National Institute of Colonization and Agrarian Reform (INCRA) was used, through the Information System for Land Reform Projects (SIPRA). The research adds to other investments in understanding the complexity of the paths and deviations of the struggle for land and in the creation of rural settlements in Brazil, starting from the state of MS.

KEYWORDS: Mato Grosso do Sul; Agrarian Reform; Rural Settlements

A propriedade latifundista, como dissera José de Souza Martins, é o "marco regulador" e a "sentinela" dos arcaísmos presentes na sociedade e na política brasileira. "Ela se propõe como sólida base de orientação social e política que freia, firmemente, as possibilidades de transformação social profunda e de democratização do país" (2011, p. 18). Ao visualizar a propriedade da terra como centro histórico de um sistema político persistente, Martins enfatiza que a questão agrária $^{3}$ engole a todos e tudo, mesmo sem que as pessoas saibam, vejam e queiram. Assim, a questão agrária "desdobrou-se numa visão de mundo, num tipo de mentalidade, presente e dominante até mesmo no querer cotidiano de quem se imagina imune a ela ou com ela descomprometido" (2011, p. 18). O Brasil mantém sua histórica concentração de terras, uma das grandes responsáveis pela desigualdade social e pela violência no campo. Em um país concentracionista, fundado no molde escravagista e que, no século XIX, também transformou a terra em "cativeiro"

\footnotetext{
${ }^{3}$ É possível dizer que, questão agrária e reforma agrária, são "irmãs univitelinas no tempo histórico" (DELGADO, 2018, p. 20), pois ambas se compreendem a partir da estrutura agrária historicamente constituída. Os conceitos se relacionam, mas são distintos. A questão agrária é mais ampla e precede a reforma agrária, pois envolve, além da estrutura fundiária, uma série de políticas que direcionam modelos de produção, posse e uso da terra. Reforma agrária trata-se de políticas que reportam à estrutura agrária, e visam minimizar e/ou alterar a estrutura fundiária concentrada de determinado país ou região.
} 
(MARTINS, 1979), produzir discussões sobre a necessidade, os impactos e os benefícios da democratização da terra incomodam um seguimento poderoso historicamente constituído.

Por reforma agrária, entende-se as ações e os programas realizados e implementados pelo Estado/Governos que visam distribuir e democratizar o acesso à terra para aqueles que querem nela trabalhar, viver e permanecer. Logo, as ações de reforma agrária visam desconcentrar a propriedade da terra, perpassando por uma questão/compromisso política/o. No Brasil, em vista da sua histórica concentração fundiária, a reforma agrária é um direito, inclusive previsto nos artigos 184 a 191, do título VII que trata "da ordem econômica e financeira", do capítulo III intitulado "a política agrícola e fundiária e da reforma agrária”, ambos da Constituição da República ${ }^{4}$. Reforma agrária, então, não trata-se de esmola aos pobres do campo, mas sim um direito constitucional.

$\mathrm{Na}$ segunda metade do século XX o tema reforma agrária tensionou diversos momentos da história do Brasil, especialmente, a partir do Golpe Militar em 1964. Destacam-se, nesse período, as políticas de reforma agrária que giraram em torno do Estatuto da Terra, criado ainda em 1964 no Regime Militar; o I Plano Nacional de Reforma Agrária, aprovado em 1985, no governo José Sarney; e o II Plano Nacional de Reforma Agrária, constituído no governo Lula, em $2003^{5}$. Na história do Brasil, nenhum governo tratou o tema reforma agrária como prioridade, mas sim como ações políticas que visavam resolver conflitos pontuais, na maior parte das vezes tensionadas pelos movimentos sociais do campo. Ou seja, a questão não foi tratada como uma política ampla e integrada a outras pastas estruturais do Estado, que abarcasse um planejamento de desenvolvimento territorial, a partir da redistribuição de terras.

Embora importantes para inserir o tema reforma agrária na agenda política do Estado, as políticas de reforma agrária foram impulsionadas,

\footnotetext{
${ }^{4}$ BRASIL. Constituição da República Federativa do Brasil de 1988. Disponível em: http://www.planalto.gov.br/ccivil 03/constituicao/constituicao.htm. Acesso em: 12 fev. 2019.

${ }^{5}$ Sobre políticas de reforma agrária na segunda metade do século XX e primeiras décadas do século XXI, ver a coletânea organizada por Fabiano Coelho e Rodrigo Simão Camacho (2018), intitulada O Campo no Brasil Contemporânea: do governo FHC aos governos Petistas Questão Agrária e Reforma Agrária.
} 
sobretudo, pelas ações dos movimentos sociais do campo. Isto é, a reforma agrária no Brasil, ou as conquistas de assentamentos rurais são fundamentalmente realizadas e executadas a partir das lutas no campo. Em um Estado latifundista, em que grande parte dos representantes políticos tem grandes propriedades de terras e também representam os interesses dos grupos que monopolizam a estrutura fundiária (CASTILHO, 2012), as ações dos movimentos sociais do campo são cruciais. A história brasileira tem evidenciado que, sem luta e pressão dos movimentos sociais, não há conquista de assentamentos rurais.

A luta pela terra no tempo presente carrega consigo marcas de uma questão agrária inacabada, de um país que não enfrentou a concentração de terras. Os tradicionais latifúndios não foram marcas que ficaram na América Portuguesa e no Império ${ }^{6}$, ainda são expressões do tempo presente (ROUSSO, 2016; VARELLA, 2012), do tempo vivido, sentido, ainda na atualidade. Os movimentos sociais do campo, as diversas lutas pela terra e na terra, assim como os acampamentos sem-terra são expressões de um tempo distante que dialogam em todo momento com o presente. Na questão agrária brasileira, presente e passado se misturam e se ressignificam, porém, a marca característica é o latifúndio.

Os movimentos sociais organizados no campo são expressões da resistência e da luta contra a histórica estrutura concentrada da terra no Brasil. Estrutura essa que gera e agrega poder: grupos que controlam e pautam políticas sobre o modelo agrícola e a alimentação; expropriam trabalhadores rurais e populações tradicionais dos seus territórios; e inculcam na sociedade uma mentalidade latifundista, como se o modelo defendido por esses grupos, a exemplo das práticas do agronegócio ${ }^{7}$ no contexto atual, caracterizasse a

\footnotetext{
${ }^{6}$ Os trabalhos de Márcia Maria Menendes Motta $(2009 ; 1998)$ e Ligia Osório Silva (2008) são relevantes para compreender os conflitos por terras nos séculos XVIII e XIX no território brasileiro.

${ }^{7}$ Entende-se agronegócio como um conjunto de sistemas abrangentes, que reúne, de forma diferenciada, os sistemas agrícolas, pecuário, industrial, mercantil, financeiro, tecnológico, científico e ideológico. No Brasil, esse modelo se desenvolveu com intensidade na década de 1990, a partir das corporações nacionais e transnacionais. Ver: Guilherme Costa Delgado (2010) e Bernardo Mançano Fernandes (2013).
} 
modernidade, geradora de riquezas para os brasileiros. Uma visão distorcida, haja vista que a concentração de terra gera riqueza para poucas famílias e empresas, sobretudo para àquelas que detêm a propriedade da terra.

A reforma agrária no estado de Mato Grosso do Sul (MS) e no Brasil é fruto da luta pela terra realizada pelos movimentos sociais rurais e das contradições da política agrícola nacional que, simultaneamente, incentivou a modernização do setor agropecuário e foi forçada a propor a criação de pequenas propriedades rurais para amenizar os conflitos agrários decorrentes da concentração fundiária. A criação de assentamento rurais constitui o principal instrumento da política de reforma agrária e deriva da relação conflituosa entre as ações do Estado/governo e a pressão exercida pelo movimentos sociais rurais. No MS, a criação de assentamentos rurais iniciou-se no ano de 1984, e foi estagnada em 2013, quando foi criado o último assentamentos rural no estado. Ou seja, há oito anos não há criação de assentamentos rurais no território sul-mato-grossense.

Nessa perspectiva, o objetivo deste artigo é refletir sobre a criação de assentamentos rurais no estado de MS, entre os anos de 1984 e 2013, considerando os contextos e os governos em que foram implementados ${ }^{8}$. O recorte temporal abrange $\mathrm{o}$ ano de criação do primeiro e do último assentamento criado em MS. Nas tabelas de dados apresentadas, também registram-se a quantidade de famílias, tamanho das áreas e média de famílias assentadas nas áreas conquistadas. As reflexões e os dados socializados são atuais, e podem contribuir para estimular outras pesquisas que abordem recortes e temáticas mais específicas. Assim, o trabalho soma-se a outros investimentos em compreender a complexidade dos caminhos e descaminhos da luta pela terra e na criação de assentamentos rurais no Brasil, a partir do estado de Mato Grosso do Sul.

$\mathrm{Na}$ construção da narrativa, além das bibliografias sobre o tema, utilizou-se informações do Instituto Nacional de Colonização e Reforma

\footnotetext{
${ }^{8}$ A pesquisa apresentada neste artigo é fruto de parcerias acadêmicas entre os dois autores no âmbito da Universidade Federal da Grande Dourados (UFGD).
} 
Agrária (INCRA), por meio do Sistema de Informações de Projetos de Reforma Agrária (SIPRA). Os dados do INCRA são ímpares e fornecem um panorama abrangente sobre as áreas de assentamentos rurais em MS. Na análise dos dados não trabalhou-se na perspectiva de que os números são absolutos e inquestionáveis. As informações não falam por si só, não há documento inocente (LE GOFF, 2003; BLOCH, 2001) ou isento de questionamentos. Os dados quantitativos podem propiciar reflexões significativas, porém, não falam sozinhos, é preciso qualificá-los, fazer perguntas e trabalhá-los dentro do contexto em que foram produzidos. Por ser responsável em planejar e executar as políticas de reforma agrária do Estado brasileiro, bem como cadastrar possíveis famílias beneficiadas por essas políticas nas unidades federativas, o INCRA, a partir de seus sistemas operacionais, dispõe de um conjunto de informações preciosas sobre estrutura fundiária e reforma agrária.

A criação de assentamentos rurais constituí um processo complexo envolvendo diferentes interesses, tanto do Estado quanto dos proprietários de terras e dos movimentos sociais de luta pela terra. No MS, a partir da década de 1980 foram criados 204 Projetos de Assentamentos (PAs), o que exigiu uma vultosa quantidade de recursos técnicos, humanos e financeiros não somente para a aquisição das propriedades partilhadas e distribuídas, mas também para promover as condições mínimas para que as famílias contempladas com lotes da reforma agrária pudessem viver e produzir, gerando a renda necessária para sua sobrevivência. Contudo, ainda há muito que se conquistar, pois diversos assentamentos no estado são precários e necessitam urgentemente de políticas públicas para fomentar estrutura básica e viabilizar os trabalhos na terra. É necessário que as políticas de reforma sejam planejadas e executadas de forma ampla, não visando única e exclusivamente a mera distribuição de terras. Sem estrutura básica para viver e meios para geração de renda, o êxito dos assentamentos rurais fica comprometido.

No MS, as modalidades de aquisição de propriedades rurais mais utilizadas foram as que envolvem indenizações, e a desapropriação por interesse social foi a forma de aquisição que prevaleceu. Contudo, apesar de 
mais conflituosa, se comparada à aquisição por compra e venda, a desapropriação é a modalidade em que o poder público atua em toda a sua plenitude constitucional, exercendo integralmente sua prerrogativa de aliar o cumprimento da função social da propriedade ao desenvolvimento regional por meio do acesso à terra. O processo de desapropriação para fins de reforma agrária é previsto na Lei Federal $n^{\circ} 8.629 / 93^{9}$. Todavia, entre a identificação de propriedades e a execução das desapropriações há diversas e distintas tensões, envolvendo os demandantes da terra, o Estado e os proprietários da área. No Brasil, os processos são morosos e a reforma agrária tem sido marcada constantemente pela violência e por mortes no campo. Terra no Brasil é sinônimo de poder. As lutas dos movimentos sociais rurais que visam denunciar os latifúndios improdutivos têm derramado o sangue de trabalhadores e trabalhadoras. Muitos pobres do campo morrem ao lutar por um direito legitimado pela Constituição do país e que lhes é negado historicamente.

As formas de obtenção de terras para fins de reforma agrária adotadas em MS foram a desapropriação ${ }^{10}$, compra e venda ${ }^{11}$, reconhecimento $^{12}$, doação $^{13}$, reversão $^{14}$ e $\operatorname{arrecadação~}^{15}$. A desapropriação por interesse social e a

\footnotetext{
${ }^{9}$ Sobre os meandros políticos e operacionais que envolvem o processo de desapropriação de terras, ver: Freitas (2020).

${ }^{10}$ A desapropriação para fins de reforma agrária é uma forma de aquisição compulsória da propriedade rural através de ato expropriatório e mediante justa e prévia indenização, em que apenas as benfeitorias são indenizadas à vista e em dinheiro, enquanto a terra e seus acessórios são quitados de forma parcelada através da emissão de Títulos de Dívida Agrária (TDA) resgatáveis em até 20 (vinte) anos.

${ }^{11}$ A criação de assentamentos por compra e venda é uma modalidade de aquisição de terras para fins de reforma agrária em que o Estado adquire de forma voluntária uma propriedade rural por meio de compra diretamente do proprietário mediante pagamento à vista ou parcelado e pelo preço de mercado.

${ }^{12} \mathrm{O}$ reconhecimento consiste no recebimento de uma propriedade rural adquirida pelos estados ou municípios, por meio de qualquer uma das formas ou modalidades de aquisição e que são, posteriormente, repassadas para a União objetivando a implantação de assentamentos rurais.

${ }^{13}$ A doação consiste na aquisição da propriedade rural por meio de um contrato pela qual a pessoa física ou jurídica transfere gratuitamente um bem de seu patrimônio para o Estado com a finalidade de criar um assentamento rural de reforma agrária.

${ }^{14}$ A reversão consiste em reverter ao patrimônio público a posse ou domínio de terras ocupadas ou destinadas irregularmente, e geralmente se dá em áreas remanescentes de colonização ou reforma agrária que foram objeto de reconcentração fundiária ou nos casos de regularização fundiária de terras públicas situadas em faixa de fronteira.

${ }^{15}$ A arrecadação consiste na incorporação ao patrimônio público de propriedades rurais vagas ou devolutas, ou seja, que não estão cobertas por títulos de domínio ou que sob as quais não pese reivindicação de posse.
} 
compra e venda foram respectivamente as modalidades de aquisição de terras mais utilizadas na criação de assentamentos rurais, sendo responsáveis pela criação de 184 projetos de assentamentos rurais no estado. Mesmo sendo muito utilizada, a modalidade de compra e venda de imóveis rurais para fins de reforma agrária foi implementada somente com a promulgação do Decreto n. $^{\circ}$ 433/92, que passou a regulamentar os procedimentos administrativos a serem observados na apuração do valor devido.

Foram criados 64 projetos de assentamentos em MS a partir de terras obtidas por compra e venda, beneficiando 2.784 famílias, em um total de 211.465,44 hectares, especialmente em áreas com manifesta tensão social, constituindo, pois, um instrumento importante para resolução de conflitos agrários. Embora, a opção por compra e venda tem gerado críticas e reações dos movimentos sociais e de estudiosos do tema (COELHO; CAMACHO, 2018), uma vez que, a reforma agrária, é vista por governos e grandes proprietários de terras como oportunidades de fazer negócios, contrariando o cerne da política a questão social - democratização da terra, geração de renda e minimização das desigualdades. O processo histórico tem evidenciado que, independente da modalidade de aquisição de terras, o Estado brasileiro necessita priorizar um orçamento suficiente para a reforma agrária e garantir condições para que os assentamentos sejam criados de forma ágil e com qualidade. O cerne da reforma agrária são as famílias a serem beneficiadas, não os ruralistas que negociam suas propriedades.

A implantação de assentamentos rurais em MS deu-se antes do lançamento do I Plano Nacional de Reforma Agrária (I PNRA), em 1985, pelo então presidente José Sarney, que substituiu Tancredo Neves, eleito indiretamente como primeiro presidente civil após o fim do Regime Militar (1964-1984). O I PNRA tinha como objetivo amenizar os conflitos agrários decorrentes da política nacional de modernização da agricultura ${ }^{16}$. Todavia, foi ainda durante o Regime Militar que o governo federal decidiu criar na região de

\footnotetext{
${ }^{16}$ Sobre o processo de modernização da agricultura no Brasil, na segunda metade do século XX, ver: José Graziano da Silva (1982).
} 
Corumbá uma série de assentamentos rurais, sendo o primeiro denominado Projeto de Assentamento Tamarineiro, em 1984, dando início ao processo de reforma agrária em MS (MENEGAT, 2009). O PA Tamarineiro é conhecido como o primeiro assentamento rural de MS e um dos precursores no Brasil. Esse assentamento foi criado sem qualquer planejamento e a partir de terras adquiridas por doação, não ensejando ônus ao Estado. Assim, foi possível sua criação precoce, antecipando-se ao lançamento do I PNRA que ainda estava em elaboração. O PA Tamarineiro foi instalado em local de difícil acesso e pouco propício para agricultura, e buscava somente a resolução de um conflito agrário local e o atendimento dos interesses da família Chamma ${ }^{17}$.

Os primeiros assentamentos rurais criados em MS, respaldados pelo I PNRA, foram os PAs denominados Retirada da Laguna (no município de Guia Lopes da Laguna), Sucuriú (no município de Chapadão do Sul) e Nioaque (no município de Nioaque), em 1985, abrigando um total de 700 famílias, sendo a maioria composta por trabalhadores rurais expulsos do campo pela expansão da atividade agropecuária promovida pela modernização da agricultura. $\mathrm{O}$ número de famílias atendidas com a criação dos primeiros assentamentos rurais no estado foi inexpressivo, se considerar a meta de assentamento de 4.400 famílias prevista no I PNRA. Também pela demanda por terras no estado, que passava por uma série de conflitos agrários e manifestações populares promovidas por milhares de famílias acampadas ao longo de rodovias, exigindo o cumprimento da política de reforma agrária.

Não se sabe ao certo o número da demanda por terras em MS no período de vigência do I PNRA, existindo divergência entre a quantidade anunciada pelo governo e a divulgada pelos movimentos sociais rurais. Porém, haviam

\footnotetext{
${ }^{17} \mathrm{O}$ grupo Chamma era ligado à produção siderúrgica no município de Corumbá até a década de 1970 quando, em razão do encerramento dessas atividades, voltou-se para a produção pecuária, mas com a necessidade de demarcar a posse de suas áreas, pois pela forma como cercou seu domínio não detinha o título de posse de boa parte das terras (MENEGAT, 2009). Deste modo, o acordo de doação de terras com o INCRA envolvia em contrapartida a regularização de outras posses que a família Chamma tinha sem regulamentação. Assim, observa-se que, a criação do PA Tamarineiro foi utilizada como moeda de troca para regularizar a propriedade da família Chamma.
} 
milhares de famílias acampadas, muitas delas "brasiguaias"18, expulsas do Paraguai, que se dirigiam para os municípios do sul do estado engrossando as fileiras de trabalhadores rurais sem-terra. Apesar do aumento dos conflitos agrários e do surgimento de diversas ocupações de terras organizadas pelos movimentos sociais rurais, no ano de 1986, somente 4 PAs foram criados em MS, totalizando 1.089 famílias assentadas. Apenas uma fração das milhares de famílias sem-terra no estado à época foram atendidas.

Mesmo não acontecendo uma mudança significativa na demanda pela reforma agrária em MS ao longo dos anos, como se pode verificar pela quantidade de famílias acampadas no estado atualmente, totalizando pouco mais de 24 mil candidatos e candidatas segundo os dados divulgados pelo INCRA (FREITAS, 2020, p. 58), a política agrária de criação de PAs inaugurada em 1984 encontra-se estagnada desde o ano de 2013, quando foi implantado o PA Nazareth, em Sidrolândia.

De 1984 a 2013 foram concluídos 173 processos de obtenção de terras pelo governo federal e/ou reconhecimento de assentamentos rurais implantados pelo governo estadual, sendo que alguns deles resultaram em vários projetos de assentamentos como no caso do PA Itamarati I, cuja propriedade foi desmembrada e dividida em quatro assentamentos rurais vinculados à Central Única dos Trabalhadores (CUT), Movimento dos Trabalhadores Rurais Sem Terra (MST), Federação dos Trabalhadores na Agricultura (FETAGRI) e Federação da Agricultura Familiar (FAF). O mesmo ocorreu no caso do PA Itamarati II, cuja propriedade foi desmembrada e dividida em cinco projetos de assentamentos, sendo destinada às famílias ligadas ao MST, a CUT, a FETAGRI, a FAF e aos Funcionários Associados da Fazenda Itamarati (FAFI). Este fato também se repetiu em outros assentamentos rurais de MS, como nos projetos do assentamento Santa Mônica (CUT, MST e FETAGRI), do Indáia em Aquidauana (CUT, FAF, FETAGRI e MST), do Avaré (CUT e FETAGRI),

\footnotetext{
${ }^{18} \mathrm{O}$ termo brasiguaio foi utilizado para se referir aos trabalhadores brasileiros que migraram para o Paraguai nas décadas de 1960 e 1970 com o objetivo de adquirir terras e construir a vida no país vizinho. Contudo, retornaram para o território brasileiro, sendo que muitos passaram a integrar os movimentos sociais de luta pela reforma agrária.
} 
do Barra Nova (MST e FETAGRI), do Volta Redonda (FAF e CUT) e do Alambari (CUT, FETAGRI e FAF), que acabaram levando o nome dos grupos que tiveram participação no processo de aquisição da propriedade.

Enquanto que, em alguns casos, uma propriedade adquirida foi transformada em vários PAs, em outras situações ocorreu o inverso, foi preciso a aquisição de várias propriedades para formar um PA, como é o caso do Aldeia, localizado no município de Bataguassu, criado a partir da aquisição das fazendas Confissão, Aldeia, São José da Alegria, Santa Luzia e Cinco Irmãos; e do Dorcelina Folador, localizado no município de Ponta Porã, criado a partir da aquisição das fazendas Entre Rios, Noroeste, Rabão, Seriema, Itá e Tucano.

\section{Gráfico 1 - Quantidade de Assentamentos criados em MS por ano (1984-2013)}

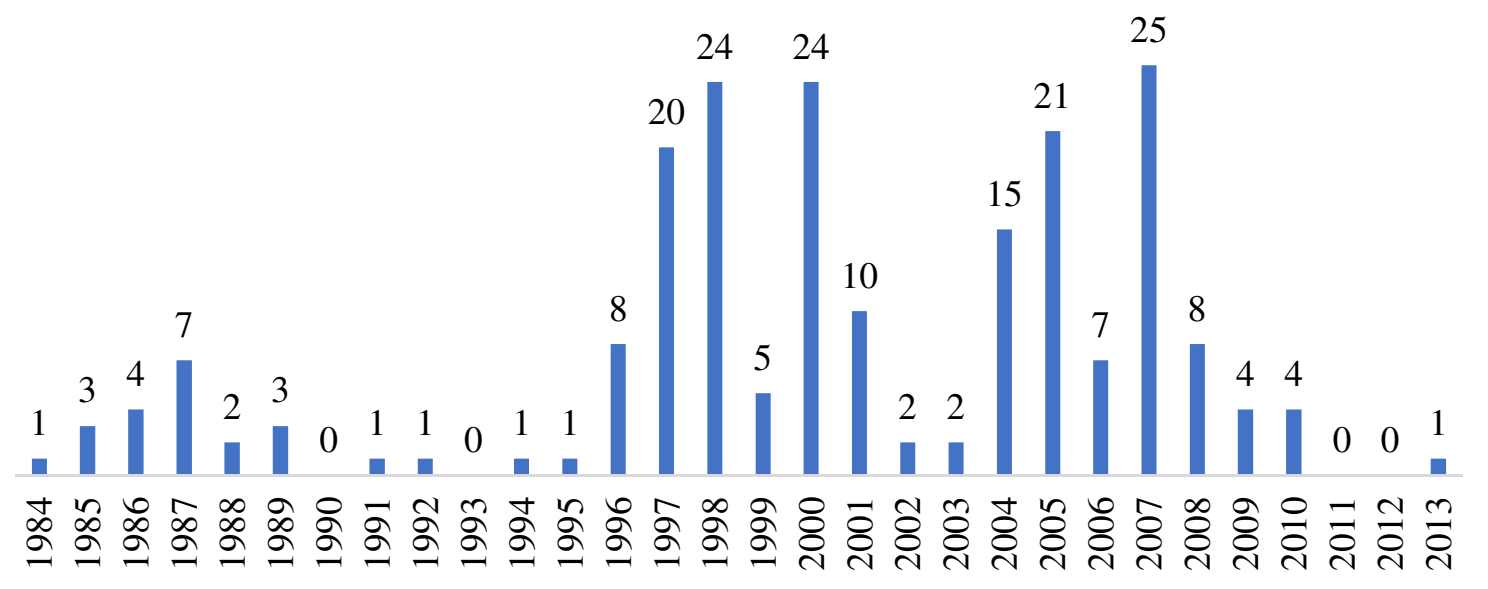

Fonte: Dados sistematizados pelos autores com base nas informações do SIPRA/INCRA.

No governo José Sarney (1985-1990) ${ }^{19}$ foram criados 19 assentamentos rurais em MS, abrigando um total de 4.305 famílias, em uma área de 126.079,00 hectares.

\footnotetext{
${ }^{19}$ Até 7 de junho de 1994, o mandato presidencial era de 5 anos, porém foi alterado para 4 anos por força da Emenda Constitucional de Revisão n ${ }^{\circ} 5$.
} 


\begin{tabular}{|c|c|c|c|c|}
\hline \multicolumn{5}{|c|}{ Tabela 1 - Assentamentos criados em MS durante o governo Sarney (1985-1990) } \\
\hline Ano & Assentamentos & Famílias & Área (ha) & $\begin{array}{c}\text { Média de área } \\
\text { por família }\end{array}$ \\
\hline 1985 & 3 & 700 & $28.729,76$ & 41,04 \\
\hline 1986 & 4 & 1.089 & $24.135,16$ & 22,16 \\
\hline 1987 & 7 & 1.039 & $43.660,89$ & 42,02 \\
\hline 1988 & 2 & 295 & $9.613,14$ & 32,58 \\
\hline 1989 & 3 & 1.182 & $19.940,04$ & 16,86 \\
\hline 1990 & 0 & 0 & 0,00 & 0 \\
\hline Total & $\mathbf{1 9}$ & $\mathbf{4 . 3 0 5}$ & $\mathbf{1 2 6 . 0 7 9 , 0 0}$ & $\mathbf{2 9 , 2 8}$ \\
\hline \multicolumn{5}{|c|}{ Fonte: Dados organizados pelos autores com base nas informações do SIPRA/INCRA } \\
\hline
\end{tabular}

O reduzido número de assentamentos rurais criados em MS, neste período, decorre, sobretudo, da forte oposição dos latifundiários preocupados com os mecanismos de desapropriação regulamentados pelo I PNRA. É preciso considerar que, o I PNRA, até a sua aprovação final em outubro de 1985, sofreu muitas alterações ao longo de suas 12 versões (SILVA, 1987, p. 62). A última versão estava radicalmente alterada em relação à proposta original, frustrando as expectativas e demandas dos trabalhadores e das trabalhadoras do campo. Para Débora Lerrer, o Plano aprovado foi "transfigurado" (LERRER, 2008, p. 66). O PNRA aprovado continha um discurso nas entrelinhas de que o Estado não iria realizar a reforma agrária desejada pelos movimentos sociais. A reforma agrária, a partir do PNRA, passou a se constituir mais em "um ato voluntário dos proprietários rurais" (FELICIANO, 2006, p. 42). O início da implantação de assentamentos rurais em MS foi um período conturbado, pois mesmo sendo obrigado a reconhecer a importância da reforma agrária para diminuição dos conflitos sociais no campo, o governo José Sarney não conseguiu atingir sequer $10 \%$ (dez por cento) da meta de criação de assentamentos previstas no plano nacional.

Outro fator que contribuiu para o não atendimento das metas estabelecidas no I PNRA foi a dúvida em relação à recepção da política agrária pela Constituição Federal promulgada em 5 de outubro de 1988, fato este que 
prejudicou a criação de novos assentamentos. A dúvida na época era se a nova Carta Magna reconheceria o direito de desapropriação da propriedade rural que não cumprisse sua função social, fato este que causou intenso debate na Assembleia Constituinte. Para Humberto Mendes de Sá Formiga, as alterações promovidas pela nova Constituição pouco acrescentaram à resolução dos conflitos no campo, embora, o processo de recriação das instituições democráticas fora importante para "construir um ambiente de estabilidade econômica e amenizar problemas sociais" (FORMIGA, 2004, p. 20).

Mesmo com a promulgação da Constituição Federal de 1988, a legislação agrária continuou como era antes, ou seja, não criou mecanismos que viabilizassem uma solução definitiva para a concentração fundiária, prevendo apenas uma melhoria na distribuição de terras. Isto é, no Brasil, o latifúndio, a concentração de terras, o poder do atraso, nunca foram ameaçados, até mesmo quando o país foi governado pelo Partido dos Trabalhadores (PT), simpatizante histórico da luta dos sem-terra.

No início da década de 1990, as ações de reforma agrária alcançaram força significativa, suscitando acirramento dos conflitos como o ocorrido em 17 de abril de 1996 no sudeste do estado do Pará, quando dezenove trabalhadores rurais sem-terra foram mortos pela polícia, episódio que ficou conhecido como Massacre de Eldorado dos Carajás. Durante esse período também ocorreram conflitos em MS entre proprietários de terras e acampados, resultando em mortes. Cita-se, por exemplo, o conflito que ocorreu em 30 de agosto de 2000, quando integrantes do MST, Silvio Rodrigues e Ranildo da Silva, foram presos, torturados e executados por pistoleiros contratados por fazendeiros da região de Rio Brilhante.

Após a promulgação da nova Constituição, que reestabeleceu as eleições pelo voto direto, o governo Fernando Collor de Melo $(1990-1992)^{20}$ criou 2 assentamentos rurais em MS, abrigando um total de 297 famílias em uma área de 9.040,84 hectares. A média de área por família assentada foi de 30,44

\footnotetext{
${ }^{20}$ O governo Collor teve início em 15 de março 1990 e terminou em 29 de dezembro de 1992 , quando renunciou ao mandato devido a abertura do processo de impeachment.
} 
hectares.

\begin{tabular}{|c|c|c|c|c|}
\hline Ano & Assentamentos & Famílias & Área (ha) & $\begin{array}{c}\text { Média de área } \\
\text { por família }\end{array}$ \\
\hline 1990 & 0 & 0 & 0,00 & 0,00 \\
\hline 1991 & 1 & 149 & $4.719,81$ & 31,67 \\
\hline 1992 & 1 & 148 & $4.321,02$ & 29,19 \\
\hline Total & 2 & 297 & $9.040,84$ & 30,44 \\
\hline
\end{tabular}

A justificativa para a pequena quantidade de assentamentos rurais criados durante o governo Collor foi a falta de regulamentação do dispositivo constitucional que previa a desapropriação para fins de reforma agrária, o que só veio ocorrer no governo Itamar Franco, que o substituiu. Destaca-se que, mesmo sem a regulamentação da nova Constituição Federal, o ex-presidente José Sarney ainda criou mais quatro projetos de assentamento em MS até o término do seu mandato, em 15 de março de 1990, o que contraria a justificativa do governo Collor para ausência de políticas agrárias durante seu mandato presidencial.

Collor e seu governo eram nitidamente contrários a organização e a ação dos movimentos sociais no campo. Ações de isolamento e repressão contra os movimentos sociais do campo marcaram o mandato do ex-presidente. A partir de 1991, por exemplo, as Secretarias Estaduais do MST foram alvo de ações da Polícia Federal, "com apreensão de documentos e prisões preventivas de lideranças dos trabalhadores rurais" (COELHO, 2017, p. 322). A repressão promovida contra os movimentos sociais do campo, além intimidar as lideranças, objetivavam também isolar os movimentos sociais de luta pela terra, especialmente, o MST. Entre as lideranças do MST o governo Collor é lembrado como o mais autoritário, inimigo da reforma agrária e do MST (FERNANDES; STÉDILE, 2005). Para os movimentos sociais do campo, a mudança de governo foi considerada um respiro diante das repressões e 
violências. O governo subsequente, de Itamar Franco, não propiciou mudanças consideráveis no cenário da reforma agrária, contudo, se colocou disposto, minimamente, a dialogar com os grupos de trabalhadores rurais sem-terra.

No governo Collor, em MS, uma propriedade foi adquirida para fins de reforma agrária, mediante compra e venda, onde foi instalado o PA São Manuel, no município de Anastácio, em 27 de fevereiro de 1992, sendo que o PA Sumatra, localizado no município do Bodoquena, apesar de criado em 1991, já havia sido adquirido em 18 de setembro de 1989, ainda durante o governo Sarney. Com a aprovação da Lei no 8.629/93, o governo Itamar Franco (19921994) promoveu a regulamentação da desapropriação prevista na Constituição Federal. Essa regulamentação não mudou os rumos da reforma agrária em MS, que continuou estagnada durante todo o governo Itamar Franco, com a criação de 1 assentamento rural (tabela 3), denominado PA São Luiz, no município de Baitaporã, abrigando 114 famílias em 1.599,61 hectares.

\begin{tabular}{|c|c|c|c|c|}
\hline \multicolumn{5}{|c|}{ Tabela 3 - Assentamentos criados em MS durante o governo Itamar (1993- } \\
\hline Ano & Assentamentos & Famílias & Área (ha) & $\begin{array}{c}\text { Média de área } \\
\text { por família }\end{array}$ \\
\hline 1993 & & & & 0,0000 \\
\hline 1994 & 0 & 0 & 0,0000 & 14,03 \\
\hline Total & 1 & 114 & $1.599,61$ & $\mathbf{1 4 , 0 3}$ \\
\hline \multicolumn{6}{|l|}{ Fonte: Dados organizados pelos autores com base nas informações do SIPRA/INCRA } \\
\hline
\end{tabular}

No governo Fernando Henrique Cardoso (FHC - 1995-2002) foram criados 94 PAs, ao longo de dois mandatos. Foram 53 assentamentos no primeiro, abrigando um total de 7.491 famílias; e 41 assentamentos no segundo mandato, abrigando 5.268 famílias. A média foi de lotes com 28 hectares por família no primeiro mandato, e lotes com 25,49 hectares por família no segundo mandato. 


\begin{tabular}{|c|c|c|c|c|c|}
\hline \multicolumn{6}{|c|}{ Tabela 4 - Assentamentos criados em MS durante o governo FHC (1995-2002) } \\
\hline Mandato & Ano & Assentamentos & Famílias & Área (ha) & $\begin{array}{c}\text { Média de área } \\
\text { por família }\end{array}$ \\
\hline \multirow{5}{*}{$\mathbf{1}^{\mathbf{0}}$} & 1995 & 1 & 319 & $10.635,58$ & 33,34 \\
\hline & 1996 & 8 & 1.422 & $35.027,69$ & 24,63 \\
\hline & 1997 & 20 & 2.691 & $72.468,71$ & 26,93 \\
\hline & 1998 & 24 & 3.059 & $91.567,31$ & 29,93 \\
\hline & Subtotal & 53 & 7.491 & $209.699,29$ & 28,00 \\
\hline \multirow{6}{*}{$2^{\circ}$} & 1999 & 5 & 192 & $4.586,25$ & 23,88 \\
\hline & 2000 & 24 & 3.010 & $77.732,38$ & 25,00 \\
\hline & 2001 & 10 & 892 & $22.482,72$ & 25,20 \\
\hline & 2002 & 2 & 1.174 & $29.496,21$ & 25,12 \\
\hline & Subtotal & 41 & 5.268 & $134.297,56$ & 25,49 \\
\hline & Total & 94 & 12.759 & $343.996,85$ & 26,96 \\
\hline
\end{tabular}

O governo FHC foi o que mais criou assentamentos rurais no Brasil e no estado de MS. Entretanto, em relação às famílias assentadas, o seu sucessor, Luiz Inácio Lula da Silva, Lula, o superou. Ter criado mais assentamentos e assentado menos famílias que o governo Lula pode ser explicado, em parte, pelo tamanho das áreas, visto que a média de aproximadamente 27 hectares por família foi superior à média das parcelas concedidas nos governos Lula (aproximadamente 16 hectares). Se comparado a governos anteriores, é significativa a quantidade de assentamentos criados e famílias assentadas em MS, todavia, a demanda por beneficiários da reforma agrária, na época, estava longe de ser suprida. Além do mais, a concentração de terras no estado continuou intocável, ou seja, a criação dos assentamentos foi muito mais pelos tensionamentos impulsionados pelas lutas dos grupos sem-terra do que vontade política em democratizar o acesso à terra. A máxima de que se não tiver luta não há conquista da reforma agrária, no Brasil, é verídica.

Embora tenha investido na criação de assentamentos, o governo FHC deixou a desejar na consolidação das áreas criadas em governos anteriores e na infraestrutura dos novos assentamentos, além de não conseguir atender a grande 
quantidade de famílias acampadas. De acordo com Bernardo Mançano Fernandes, no governo FHC, os assentamentos rurais foram precarizados, “implantados como projetos incompletos, que além de não terem infraestrutura básica, a maior parte também não recebeu crédito agrícola e de investimento" (2003, p. 3).

No governo Lula (2003-2010) foram criados 86 assentamentos rurais em MS, sendo 45 projetos no primeiro mandato, abrigando um total de 9.666 famílias; e 41 assentamentos rurais no segundo mandato, de $1^{\circ}$ de janeiro de 2007 a $1^{\circ}$ de janeiro de 2011, abrigando 4.662 famílias. A média de lotes foi aproximadamente 15 hectares por família no primeiro mandato; no segundo mandato lotes em torno de 18 hectares por família.

\begin{tabular}{|c|c|c|c|c|c|}
\hline \multicolumn{6}{|c|}{ Tabela 5 - Assentamentos criados em MS no governo Lula (2003-2010) } \\
\hline \multirow{6}{*}{$\begin{array}{c}\mathbf{1}^{\circ} \\
\text { Mandato }\end{array}$} & Ano & Assentamentos & Famílias & Área (ha) & $\begin{array}{c}\text { Média de } \\
\text { Área por } \\
\text { Família }\end{array}$ \\
\hline & 2003 & 2 & 18 & 500,02 & 27,77 \\
\hline & 2004 & 15 & 3.811 & $60.308,90$ & 15,82 \\
\hline & 2005 & 21 & 4.953 & $71.806,76$ & 14,49 \\
\hline & 2006 & 7 & 884 & $13.655,75$ & 15,44 \\
\hline & Subtotal & 45 & 9.666 & $146.271,43$ & 15,13 \\
\hline \multirow{6}{*}{$\begin{array}{c}2^{\circ} \\
\text { Mandato }\end{array}$} & 2007 & 25 & 3.352 & $52.044,40$ & 15,52 \\
\hline & 2008 & 8 & 549 & $17.136,60$ & 31,21 \\
\hline & 2009 & 4 & 401 & $6.641,35$ & 16,56 \\
\hline & 2010 & 4 & 360 & $7.098,16$ & 19,71 \\
\hline & Subtotal & 41 & 4.662 & 82.920,51 & 17,78 \\
\hline & Total & 86 & 14.328 & 229.191,94 & 15,99 \\
\hline
\end{tabular}

Apesar de o governo Lula ter criado menos assentamentos rurais que o governo FHC, em seus mandatos, registram-se mais famílias assentadas em MS, pois, enquanto no governo FHC foram assentadas 12.759 famílias, no 
governo Lula foram assentadas 14.328 famílias. O governo Lula priorizou o atendimento de um maior número de famílias, ainda que fosse necessário a diminuição do tamanho das parcelas. É importante salientar que não estamos considerando a qualidade das terras adquiridas em ambos os governos. Isso porque um lote menor, em terras melhores, como é o exemplo do PA Itamarati, em Ponta Porã, é mais produtivo do que alguns lotes maiores, como os do PA Casa Verde, em Nova Andradina, que, embora sejam maiores, têm produtividade reduzida por conta da baixa qualidade do solo. Ressalta-se ainda que, os governos Lula, diferentemente dos governos FHC, avançaram em algumas políticas de reforma agrária, como: "reassentamento de atingidos por obras públicas, assistência técnica, créditos agrícolas, infraestrutura nos assentamentos e diálogo com os movimentos sociais" (COELHO, 2014, p. $395)$.

O governo Lula priorizou a compra de terras como forma de aquisição de propriedades rurais para a reforma agrária em MS. Durante seus mandatos foram adquiridas 56 propriedades pela modalidade compra e venda, enquanto no governo FHC foram adquiridas 3 propriedades nesta modalidade. Por outro lado, em MS, durante o governo FHC foram realizadas 83 desapropriações voltadas à reforma agrária, enquanto que no governo Lula foram realizadas 21 , o que evidencia o perfil da política de reforma agrária estabelecido por cada um dos governos.

Ao priorizar a aquisição por compra e venda e não considerar outras modalidades gerou-se uma contradição na política fundiária local, pois, ao intensificar a criação de assentamentos rurais via compra e venda, contribuiu para o aquecimento do mercado de terras, elevando o valor das propriedades que, por sua vez, encareceu e dificultou a aquisição de outros imóveis rurais para reforma agrária. Além disso, deixou-se de promover uma melhor distribuição fundiária, na medida em que os recursos pagos pelas terras aos antigos proprietários dos imóveis adquiridos acabaram sendo utilizados para reinvestir na aquisição de novas propriedades. Cita-se, como exemplo, o fazendeiro Olacir de Moraes, que deixou de ser o rei da soja em MS 
(denominação em razão da produção que obtinha na fazenda Itamarati, em Ponta Porã, parte dela vendida ao Estado para criar o assentamento Itamarati), para se tornar o rei da soja na Bolívia e também o rei do algodão no MT, culturas que, em ambos os lugares, demandavam ampla dimensão de terras.

Em relação à aquisição de novas propriedades por aqueles que vendiam terras para reforma agrária, também destaca-se o caso da Fazenda Eldorado, localizada no município de Sidrolândia, que foi adquirida do grupo agropecuário Bertin por compra e venda, em 2005. Com o pagamento recebido do governo, este grupo adquiriu a Fazenda Santo Antônio no município de Itaquiraí que, por conseguinte, também foi adquirida por compra e venda para criação dos assentamentos Santo Antônio, Itaquiraí, Caburey e Foz do Rio Amambaí. Percebe-se, nessas práticas, que a reforma agrária, infelizmente, foi visualizada por latifundiários como balcão de grandes negócios.

Em MS, no final do segundo mandato do governo Lula, houve diminuição na aquisição de terras para criação de assentamentos rurais, o que pode ser explicado, em parte, pelo aumento do preço dos imóveis provocado pelo próprio governo e associado à balança comercial favorável aos produtos agrícolas brasileiros, motivando investimentos estrangeiros no território e encarecendo o preço das terras. A diminuição na criação de assentamentos rurais também pode ser explicada pela mudança de postura do governo em relação à política agrária com fim do II PNRA, quando buscou-se muito mais a consolidação dos projetos de assentamentos existentes do que a criação de novos assentamentos. Sobre esse assunto, Sedeval Nardoque, Danilo S. Melo e Mieceslau Kudlavicz, observam que "houve a criação e aumento de investimentos para políticas públicas e programas sociais voltados para a agricultura familiar camponesa, destacando-se o PAA $^{21}$, o PNAE $^{22}$ e a nova perspectiva territorial aplicada nos territórios rurais" (2018, p. 645). A prioridade passou a ser investir em políticas sociais voltadas para a agricultura

\footnotetext{
21 Programa de Aquisição de Alimentos (PAA), criado em julho de 2003, e tem como finalidades centrais a promoção do acesso à alimentação e incentivo à agricultura familiar.

${ }^{22}$ Programa Nacional de Alimentação Escolar (PNAE), que oferece alimentação escolar e ações de educação alimentar e nutricional aos estudantes da Educação Básica pública.
} 
familiar e não mais na criação de novos assentamentos.

No primeiro mandato do governo Lula foi elaborado e implementado o II Plano Nacional de Reforma Agrária: paz, produção e qualidade de vida no meio rural, organizado pela equipe do então ministro de Estado do Desenvolvimento Agrário, Miguel Soldatelli Rosseto. O plano objetivava assentar 400 mil famílias, entre os anos de 2003 e 2006; financiar a aquisição de terras para 130 mil famílias e regularizar as terras de 500 mil famílias. No contexto em que foi elaborado, o II PNRA gerou muitas críticas e resistências dos movimentos sociais e estudiosos do tema, pois o mesmo não era entendido como estrutural, e sim uma política compensatória, para resolver problemas pontuais. Isto é, não tocava na concentração de terras e não resolvia a demanda dos sem-terra no Brasil. O Plano não foi executado em sua plenitude de metas e não obteve sucesso. Conforme Fernandes (2013), em dois mandatos, conseguiu alcançar em $37 \%$ a meta que o próprio governo estabeleceu.

Pós-governo Lula pouco foi feito em termos de criação de assentamentos para a reforma agrária em MS. No governo Dilma Rousseff foi criado 1 assentamento rural, denominado PA Nazerth, localizado no muncípio de Sidrolândia, com 2.491,73 hectares, abrigando 171 famílias.

\begin{tabular}{|c|c|c|c|c|c|}
\hline \multicolumn{6}{|c|}{ Tabela 6 - Assentamentos criados em MS no governo Dilma (2011-2013) } \\
\hline \multirow{5}{*}{$\begin{array}{c}1^{\circ} \\
\text { Mandato }\end{array}$} & Ano & Assentamentos & Famílias & Área (ha) & $\begin{array}{c}\text { Média de } \\
\text { Área por } \\
\text { Família }\end{array}$ \\
\hline & 2011 & 0 & 0 & 0,00 & 0,00 \\
\hline & 2012 & 0 & 0 & 0,00 & 0,00 \\
\hline & 2013 & 1 & 171 & $2.491,73$ & 14,57 \\
\hline & Total & 1 & 171 & $2.491,73$ & 14,57 \\
\hline
\end{tabular}

O PA Nazerth foi implantado em uma propriedade que já havia sido adquirida em 29 de abril de 2010, ainda no governo Lula. No cenário nacional, os números não foram diferentes. Oliveira destaca que "o governo Dilma no 
primeiro mandato garante ter assentado 105 mil famílias, todavia, assentou apenas e tão somente 37 mil famílias em assentamentos novos" (OLIVEIRA, 2015, p. 29), evidenciando que, assim como no governo Collor, o governo Dilma foi um dos que menos fez pela reforma agrária em se tratando da criação de assentamentos rurais e famílias assentadas. Por outro lado, o governo da petista se distancia significativamente das características do governo Collor por manter e intensificar fomento agrícola para os assentamentos criados, com destaque aos financiamentos do Programa Nacional da Agricultura Familiar (PRONAF), compra de alimentos para merenda escolar através do PAA e do PNAE, dentre outros investimentos que implicavam compromissos com as famílias assentadas. Deste modo, a reforma agrária é constituída a partir de um conjunto de contradições, e por caminhos não retilíneos. O governo Dilma fomentou o desenvolvimento dos assentamentos, mas cessou a criação de novas áreas e não enfrentou a concentração histórica de terras no país.

Essa situação também pode ser explicada com base na crise econômica que o país passou desde o ano de 2008, cujos reflexos foram sentidos mais significativamente durante o primeiro mandato de Dilma Rousseff e pelo arrefecimento da luta pela terra, tendo como consequência a estagnação da reforma agrária em MS. Nessa perspectiva, Claudemir Martins Cosme associa o baixo índice de assentamentos rurais a queda de ações dos próprios movimentos sociais rurais: "[...] é nítido que o resultado pífio dos governos Dilma com relação a criação de novos assentamentos rurais, com certeza, está atrelado à queda e manutenção dos baixos índices de pessoas envolvidas em conflitos, principalmente, em seu primeiro governo" (2016, p. 336).

Pelos números da reforma agrária em MS é possível dizer que a criação de assentamentos rurais, em grande parte, não foi fruto de políticas públicas planejadas, mas uma reação política compensatória para amenizar os conflitos agrários e atender as reivindicações dos movimentos sociais rurais, principalmente, por meio das ocupações de terras. Dessa forma, quanto menor o número de ocupações, menor é o número de assentamentos criados, considerando que os governos criam assentamentos rurais quando são 
pressionados. A lógica do Estado é concentracionista. A reforma agrária no Brasil é um processo político e depende fundamentalmente dos tensionamentos produzidos pelos movimentos sociais rurais.

Os governos que mais assentaram famílias em MS (e também no Brasil) foram FHC e Lula. Isso não se deve somente por terem sido reeleitos, uma vez que, considerando os mandatos em separado, ainda assim, esses governos assentaram mais famílias no estado. A partir dos dados é possível verificar que, enquanto no governo Sarney (1985-1989) a média de tamanho dos lotes era de quase 30 hectares, nos governos FHC (1995-1998) e (1999-2002) o tamanho médio dos lotes foram sendo reduzidos, respectivamente 28 e 25 hectares. Já nos governos Lula (2003-2006) e (2007-2010) o tamanho dos lotes foram ainda menores, de 15 e 16 hectares respectivamente, o que pode explicar o aumento da quantidade de famílias assentadas, uma vez que o tamanho do lote pode influenciar no custo por famílias, pois, diminuindo o tamanho do lote é possível aumentar o número de famílias beneficiadas. A diferença no tamanho dos lotes traz outro aspecto a ser considerado, como aponta Menegat (2009), que é o da qualidade das terras desapropriadas. Os primeiros assentamentos rurais criados em MS ocorreram em áreas onde os processos de desapropriação eram mais acessíveis, mas nem sempre propícios para produção familiar, como os casos dos PAs Casa Verde, Taquaral e Monjolinho.

O processo de criação de assentamentos rurais em MS passou por uma estagnação a partir do ano de 2011, durante o primeiro mandato do governo Dilma, que, apesar da ocorrência de diversas ocupações de terras, houve a criação de um assentamento rural. Além da prioridade no desenvolvimento interno dos assentamentos, durante os governos Lula e Dilma foram criados programas e políticas sociais destinados aos assentamentos rurais, como é o caso da Assistência Técnica e Extensão Rural (ATER) ${ }^{23}$, do Programa Luz para

\footnotetext{
${ }^{23}$ A ATER desenvolve ações e projetos que visam desenvolver a renda e a qualidade de vida das famílias assentadas, aperfeiçoando sistemas de produção, propiciando acesso a recursos, serviços e renda.
} 
$\operatorname{Todos}^{24}$, do PAA e do PNAE; bem como o aumento dos valores destinados ao Plano Safra $^{25}$. A reforma agrária não se trata apenas de uma mera política assistencialista de distribuição de terras, pois além da terra existem outras demandas para se permanecer e viver com dignidade nos assentamentos. As famílias precisam de políticas de saúde, educação, saneamento básico, cultura, esporte, lazer, créditos, acessibilidade, infraestrutura e serviços.

A criação de assentamentos rurais, tida como principal ação da reforma agrária, é fruto da luta pela terra empreendida pelos movimentos sociais rurais e das contradições da política agrícola que incentivou historicamente a concentração fundiária. A reforma agrária em MS esteve (e está) ligada ao contexto político brasileiro, tendo início em 1984 e encontra-se estagnada desde 2013. De 1984 a 2013 foram criados 204 PAs em MS, a partir da aquisição de propriedades rurais, principalmente, por meio da desapropriação e da compra e venda de imóveis.

Os assentamentos rurais criados em MS estão relacionados às tensões dos contextos e as ações dos grupos que lutam pela terra. Isto é, a conquista dos assentamentos rurais está associada muito mais aos grupos que se organizam e lutam pela reforma agrária do que por uma política planejada dos governos. Se há lutas existe maior possibilidade de criação de assentamentos rurais. O cenário da reforma agrária no Brasil é tenso, lastimável, e não tem perspectivas de melhoras. O presidente Jair Messias Bolsonaro, eleito em 2018, representante político da extrema-direita, é publicamente defensor dos ruralistas e contrário aos movimentos sociais de luta pela terra. Assim, é pouco provável a retomada da criação de assentamentos rurais em MS, tanto pelo cenário político nacional quanto pela redução das manifestações e das ocupações de terra, apesar da existência de uma grande demanda pela reforma agrária no

\footnotetext{
${ }^{24}$ O Programa Luz para Todos visa levar energia elétrica às regiões rurais e/ou às casas que ainda não tem esse serviço. A iniciativa é coordenada pelo Ministério de Minas e Energia, operacionalizada pela Eletrobrás e executada pelas concessionárias de energia elétrica em parceria com os governos estaduais.

${ }^{25}$ O Plano Safra é lançado anualmente pelo Governo Federal e objetiva fomentar créditos para investir e custear as produções no país. Notadamente, o Plano Safra vem sendo sistematizado de forma desigual, privilegiando a produção nas grandes propriedades.
} 
estado. Entretanto, a história é movimento, e os movimentos sociais do campo tem ensinado que as conquistas são construídas no caminhar.

\section{Referências}

BLOCH, Marc. Apologia da história ou o ofício de historiador. Rio de Janeiro: Jorge Zahar, 2001.

BRASIL. Constituição da República Federativa do Brasil de 1988. Disponível em: http://www.planalto.gov.br/ccivil_03/constituicao/constituicao.htm. Acesso em: 12 fev. 2019.

CASTILHO, Alceu Luís. Partido da Terra: como os políticos conquistam o território brasileiro. São Paulo: Contexto, 2012.

COELHO, Fabiano. Entre o Bem e o Mal: representações do MST sobre os presidentes FHC e Lula (1995-2010). 2014b. 440f. Tese (Doutorado em História) - Universidade Federal da Grande Dourados, Dourados.

COELHO, Fabiano. Descaso com a Reforma Agrária e Repressão Contra os Movimentos Sociais: representações do MST sobre Collor (1990- 1992). Antíteses. Londrina/PR, v. 10, n. 19, p. 311-331, jan./jun. 2017.

COELHO, Fabiano; CAMACHO, Rodrigo Simão (Orgs.). O Campo no Brasil Contemporâneo: do governo FHC aos governos Petistas (Questão Agrária e Reforma Agrária - Vol. I). Curitiba: CRV, 2018.

COSME, Claudemir M. Os Governos do PT e os Descaminhos com a Questão Agrária no Brasil: contribuições para um diálogo polêmico, necessário e imprescindível à classe trabalhadora. PEGADA - A Revista da Geografia do Trabalho. Presidente Prudente/SP, v. 17, n. 1, p. 312-343, jul. 2016.

DELGADO, Guilherme Costa. A Questão Agrária e o Agronegócio no Brasil. In: CARTER, Miguel (Org.). Combatendo a Desigualdade Social: o MST e a reforma agrária no Brasil. São Paulo: Editora UNESP, 2010. p. 81-112.

DELGADO, Guilherme Costa. Questão Agrária Hoje. In: COELHO, Fabiano; CAMACHO, Rodrigo Simão (Orgs.). O Campo no Brasil Contemporâneo: do governo FHC aos governos Petistas (Questão Agrária e Reforma Agrária Vol. I). Curitiba: CRV, 2018. p. 17-28.

FELICIANO, Carlos A. Movimento Camponês Rebelde: a reforma agrária no Brasil. São Paulo: Contexto, 2006.

FERNANDES, B. M. Reforma Agrária no Governo Lula: a esperança. Revista Nera. Presidente Prudente, 2003.

FERNANDES, Bernardo M.; STEDILE, João P. Brava Gente: a trajetória do MST e a luta pela terra no Brasil. $3^{a}$ Ed. São Paulo: Editora Fundação Perseu Abramo, 2005. 
FERNANDES, Bernardo M. A Reforma Agrária que o Governo Lula fez e a que pode ser feita. In: SADER, Emir (Org.). Lula e Dilma: 10 anos de governos pós-neoliberais no Brasil. São Paulo: Boitempo; Rio de Janeiro: FLACSO Brasil, 2013. p. 191-205.

FREITAS, André A. R. de. A reforma agrária em Mato Grosso do Sul: os dilemas e possibilidades nos assentamentos rurais a partir de dados do INCRA. Dissertação (Mestrado em Sociologia). 2020. 187f. Universidade Federal da Grande Dourados, Dourados.

FORMIGA, Humberto M. de Sá. A Constituição Federal de 1988 e a Questão Cartográfica. Brasília: Senado, 2004.

ROUSSO, Henry. A Última Catástrofe: a história, o presente e o contemporâneo. Rio de Janeiro: Editora FGV, 2016.

LE GOFF, Jacques. História e Memória. 5 ${ }^{\text {a }}$ Ed. Campinas: Editora da Unicamp, 2003.

LERRER, Debora F. Trajetórias de Militantes Sulistas: nacionalização e modernidade do MST. 2008. 197 f. Tese (Doutorado em Ciências Sociais). Universidade Federal Rural do Rio de Janeiro - CPDA/UFRRJ, Rio de Janeiro.

MARTINS, José de Souza. A Política do Brasil: lúmpen e místico. São Paulo: Contexto, 2011.

MARTINS, José de S. O cativeiro da terra. São Paulo: Ciências Humanas, 1979.

MENEGAT, Alzira S. No Coração do Pantanal: assentados na lama e na areia, as contradições entre os projetos do estado e dos assentados no assentamento Taquaral - MS, Dourados: Ed. UFGD, 2009.

MOTTA, Márcia Maria Menendes. O Direito à Terra no Brasil. A gestação do conflito (1795/1824), São Paulo: Alameda, 2009.

MOTTA, Márcia Maria Menendes. Nas Fronteiras do Poder: conflito e direito à terra no Brasil do século XIX. Rio de Janeiro: Arquivo Público do estado do Rio de Janeiro/Vício de Leitura, 1998.

NARDOQUE, Sedeval; MELO, Danilo S.; KUDLAVICZ, Mieceslau. Questão Agrária em Mato Grosso do Sul e seus desdobramentos pós-golpe de 2016.

Revista OKARA. João Pessoa/PB, v. 12, n.2 p. 624-648, 2018.

OLIVEIRA, Ariovaldo U. de. Camponeses, indígenas e quilombolas em luta no campo: a barbárie aumenta. In: Conflitos no Campo. (Coordenação: Antônio Canuto, Cássia Regina da Silva Luz, Thiago Valentin Pinto Andrade), CPT Nacional: Brasil, 2015.

SILVA, José Graziano da. A Modernização Dolorosa. Rio de Janeiro: Zahar Editores, 1982.

SILVA, Ligia Osório. Terras Devolutas e Latifúndio: efeitos da lei de 1850. Campinas-SP: Editora da UNICAMP, 2008. 
SILVA, José Graziano da. Caindo por Terra: crises da reforma agrária na Nova República. São Paulo: Busca Vida, 1987.

VARELlA, Flávia Florentino et. al. (Orgs.). Tempo Presente \& Usos do Passado. Rio de Janeiro: Editora FGV, 2012.

Recebido em: 14 de setembro de 2020 Aceito em: 12 de agosto de 2021 